\title{
Virtual Reality Therapy for Depression and Mood in Long-Term Care Facilities
}

\author{
Kevin Zhai 1,2,", Azwa Dilawar ${ }^{1}$, Mohammad S. Yousef ${ }^{1}$, Sean Holroyd ${ }^{2,}{ }^{*}$, Haithem El-Hammali ${ }^{3, *}$ and Marwa Ab- \\ delmonem ${ }^{3, *}$ \\ 1 Premedical Unit, Weill Cornell Medicine-Qatar, Cornell University, Doha, P.O. Box 24144, Qatar; \\ azd4001@qatar-med.cornell.edu (A.D.); msy2001@qatar-med.cornell.edu (M.S.Y.) \\ 2 Department of Physiology and Biophysics, Weill Cornell Medicine-Qatar, Cornell University, Doha, P.O. Box \\ 24144, Qatar \\ 3 VCU School of the Arts in Qatar, Virginia Commonwealth University, Doha, P.O. Box 8095, Qatar \\ * Correspondence: kez4003@qatar-med.cornell.edu (K.Z.); smh2010@qatar-med.cornell.edu (S.H.); haelham- \\ mali@vcu.edu (H.E.); miabdelmonem@vcu.edu (M.A.)
}

\begin{abstract}
Virtual reality (VR) describes a family of technologies which immerse users in sensorily-stimulating virtual environments. Such technologies have increasingly found applications in the treatment of neurological and mental health disorders. Depression, anxiety, and other mood abnormalities are of concern in the growing elderly population - especially those who reside in long-term care facilities (LTCFs). The transition from the familiar home environment to the foreign LTCF introduces a number of stressors that can precipitate depression. However, recent studies reveal that VR therapy (VRT) can promote positive emotionality and improve cognitive abilities in the elderly, both at home and in LTCFs. VR thus holds potential in allowing elderly individuals to gradually adapt to their new environments - thereby mitigating the detrimental effects of place attachment and social exclusion. Nevertheless, while the current psychological literature is promising, the implementation of VR in LTCFs faces many challenges. LTCF residents must gain trust in VR technologies, care providers require training to maximize the positive effects of VRT, and decision makers must evaluate both the opportunities and obstacles in adopting VR. Here, we concisely review the implications of depression related to place attachment in LTCFs, and explore the potential therapeutic applications of VR.
\end{abstract}

Keywords: depression, virtual reality (VR), virtual reality therapy (VRT), long-term care facility (LTCF), mood disorder, place attachment, neuro-architecture

\section{Overview}

Virtual reality (VR) is the use of various technologies to digitally simulate or recreate an environment in which an observer can realistically hear, see, and/or feel as though they are a part of the simulation [1]. This dynamic perceptualization is achieved through technologies such as wearable head-mounted displays (HMDs), noise cancellation headsets, and other multimodal stimuli to immerse the wearer in the virtual atmosphere [1]. While VR has been a critical training tool in the fields of aviation, military combat, and surgery, it has recently shifted towards clinical psychology and therapy [2]. In fact, with the decreasing costs and increasing accessibility of digital media, VR has significant potential in reconstructing conventional approaches to patient care [3].

VR is a popular topic in psychological research studies for its potential in treating various mental disorders such as schizophrenia, post-traumatic stress disorder (PTSD), anxiety, and depression. Psychotherapy experts rank VR as one of the top psychological interventions with an overall positive growth projection in the coming decades [4]. Rothbaum and colleagues first assessed the clinical effects of VR therapy (VRT) on acrophobic college students [5]. Their study established the efficacy of VRT for trauma and anxiety, and provided a basis for further studies on other psychiatric illnesses [6]. With 
its ability to continuously expose patients to traumatic experiences or threats on a regular basis, VR can train patients to cope with, and eventually eliminate, the fears and negative emotions associated with stressful experiences [6]. One particular demographic that could benefit from the psychological and therapeutic effects of VR is elderly individuals who reside in long-term care facilities (LTCFs).

An increasing number of elderly people prefer to age-in-place until they become unable to care for their needs [7]. The choice of moving to a LTCF, however, often becomes inevitable at a certain stage due to deteriorating health conditions. This inevitability, along with demographic changes due to continuous increases in life expectancy, has become a concern [8]. Scholars such as Schwarz and Brent argue that the proportion of elderly people aged 80 years or older is expected to triple by 2040 [7]. In the United States of America, the age structure of the overall population is projected to change tremendously in the next decade: from 13 percent of the population aged 65 and older in 2010 to around 20 percent in 2030 [9]. Hence, there is a need for social infrastructure to accommodate the physical and psychological needs of this growing population that may transition into LTCFs.

Transitioning into a LTCF may cause severe distress and amplify pre-existing mental health impairments, corresponding to a higher rate of depression of nursing home residents when compared to non-residents [10]. Furthermore, age-related cognitive decline and desires for a familiar environment can further an elderly individual's mental deterioration. As mental illnesses can exacerbate other underlying health conditions such as cardiovascular diseases, afflicted individuals may require more demanding and attentive care [11]. VR can serve as a tool to aid the adjustment of the elderly into new LTCF environments by immersing them in a familiar space to relieve stress or familiarizing them with their new surroundings with continuous exposure. VRT can, therefore, mitigate the negative mental health trends seen in individuals in care homes.

\section{Place Attachment in LTCFs}

An individual's environment shapes their view and perception of life, and therefore plays a critical role in their psychological wellbeing. Systematic reviews indicate that most elderly individuals prefer to remain in their current residences rather than transfer into facilities [12]. Alongside the other physical health impairments associated with old age, transitioning from the comfort of their homes into LTCFs causes detrimental cognitive responses in the elderly. Nevertheless, long-term institutional care is necessary for some elderly individuals due to the severity of an illness or the lack of an attentive caregiver at home [7]. Moving to a LTCF is extraordinarily stressful and involves nostalgia [13]. In Environment-Behavior research, nostalgia is considered a result of place attachment, an emotional bond that links a person to a place [8]. A common mechanism that explains this bond is proximity-maintaining behavior [14,15]. As previously mentioned, individuals who exhibit strong attachment to certain places are likely to disregard important opportunities just to physically remain in those places [16].

A newly admitted LTCF resident faces a number of challenges associated with forming new social connections, inadequate privacy, adapting to a new institutional setting, and lack of homelike qualities [17]. Attachment to one's home complicates the transition into LTCFs. The degree of place attachment and the person's readiness to adapt to a new environment influence the smoothness of the transition and consequent stress levels. Bernard and Rowles argue that relocating to a LTCF can be traumatizing for some people due to their inexperience in changing homes throughout their life [14]. Jones et al. defined a transition as a passage between two relatively stable periods of time, in which an individual moves from one life phase to another. A transition is a process in which the person has to develop new skills, relationships, and coping strategies $[14,18]$.

Manzo and Wright shed light on the relationship between place attachment theory and the ability to transition into a new place. They suggest that in the era of increased mobility, the place attachment theory can be used to distinguish mechanisms through which people become attached even to alien places [15]. As Bernard and Rowles wrote; 


\begin{abstract}
"theories of place attachment and identity emphasize domains of belonging in a more process-oriented and differentiated way. Place attachment is not only related to attitudes, but also to a gamut of processes operating when people form affective, cognitive, behavioral, and social bonds to the environment, thereby, transforming a space into a place" [14]. Place attachment dynamics involving interrelated processes between people and places are called place processes. Examples of these processes include place identity, a process in which people view a place as a significant part of their world, and place interaction, which refers to the typical going-ons in a place [15]. In a well-liked place, all place processes are sophisticatedly interconnected; feeling at-home is being fit in a certain place and being able to continuously engage in place-making processes [15]. In other words, the degree of place attachment pre-determines a person's willingness and ability to transition into a new place such as a LTCF.
\end{abstract}

\title{
3. Depression in LTCFs
}

\subsection{Causation and Neural Mechanisms of Depression in LTCFs}

As discussed above, the transition into a LTCF is a significantly stressful event for the elderly, especially during the first four weeks following admission [19]. A major reason for this transitional stress is the disruption of place attachment bonds. According to Scannell and Gifford, maintaining proximity to one's place of attachment can be beneficial in many respects, as this provides emotional healing, cognitive restoration, belongingness, and escape opportunities from daily stressors [20]. Relocation to an entirely foreign place, without the trappings of home and family, can be psychologically devastating. As such, Texas senior home residents reported losses of independence, disruptions of continuity with their past (familiar) lives, and loneliness to be precipitating factors (stressors) in their negative moods and/or depression [10].

The Diathesis-Stress Model of mental disorders holds that certain individuals have genetic, anatomical, and/or psychological predispositions that remain dormant until activated by a source of stress [21]. Predispositions for depression include alterations in brain structure, especially in the bilateral amygdala, hippocampus, and dorsolateral prefrontal cortex (PFC). These neuroanatomical changes have been found in first-degree relatives of patients with depression, suggesting a mechanism of risk [22]. Moreover, stressful events, such as serious housing problems and separation from friends or loved ones, are causally related to depression [23].

Depression is characterized by symptoms such as persistent disturbances of mood, loss of interest in activities, sleep abnormalities, feelings of guilt, loss of energy, impaired concentration, changes in appetite, psychomotor agitation, and in some cases suicidal ideation [22]. These psychological and cognitive symptoms may manifest as a result of neurochemical and neuroanatomical changes precipitated by stress. As illustrated in Figure 1, transitional stress immediately activates the hypothalamic-pituitary-adrenal (HPA) axis. The hypothalamus releases corticotropin release factor (CRF) and vasopressin (AVP), which stimulate the release of adrenocorticotropic hormone (ACTH) from the pituitary gland. ACTH causes the adrenal cortex to release cortisol, the stress hormone [24,25]. Among other functions, cortisol downregulates hippocampal neurogenesis, leading to a decrease in hippocampal volume and consequent memory deficits [25].

Over a longer term, stressors in LTCFs decrease the levels of circulating neurotransmitters (NTs) such as norepinephrine (NE), serotonin (5-HT), and dopamine (DA). NE and 5-HT ordinarily interact with the medial PFC to regulate mood, sleep, appetite, and other bodily functions. Consequently, downregulation of these NTs leads to the low mood and sadness that are characteristic of depression [26]. These NTs also interact with the amygdala, the portion of the brain responsible for emotions and fear conditioning. Their dysfunction can lead to anxiety, which often co-occurs with depression. In contrast, DA is heavily implicated in learning and the reward system, acting in conjunction with the brain's pleasure centers. DA's downregulation correspondingly decreases pleasure and intrinsic motivation, leading to a general loss of 
interest [26]. Finally, a clinical study on patients with late-life depression by Smith and colleagues detected increased levels of $\mathrm{N}$-acetylaspartate in the posterior cingulate cortex. They also found associations between decreasing levels of glutamate and glutathione, and decreasing symptom severity [27].

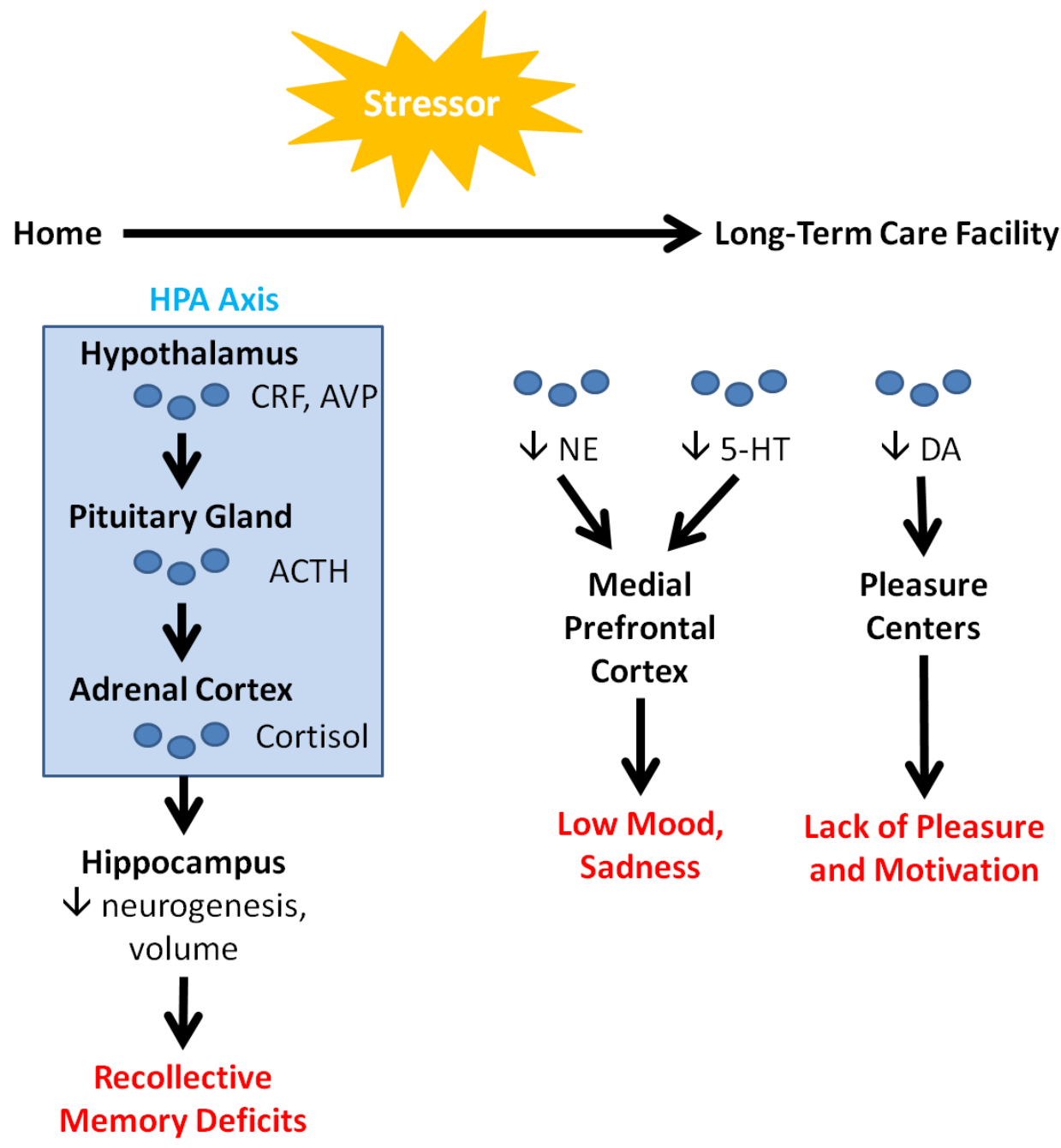

Figure 1. Neurological factors in depression. Acute and chronic stressors activate the HPA axis and modulate neurotransmitter levels, leading to cognitive and emotional consequences.

While the neural mechanisms of depression are well established, measuring depression in LTCF residents can be a difficult task. As stress is a major causal factor in depression in LTCF residents, measurement of the levels of cortisol, the hormone associated with stress, would ideally be able to confirm diagnosis. Blood cortisol levels can be matched to the degree of depression in some cases of acute and severe depression [28,29]. However, in mild, chronic, or atypical depression, variability exists in the responsiveness of the HPA axis to stressors [30-33]. As such, other factors may be at play with regards to the HPA axis's relationship with depression; these include changes in the glucocorticoid receptors, the mineralocorticoid receptors, or the responsiveness of the axis to AVP and CRF [33]. Therefore, the hormone cortisol cannot be used alone as a marker of depression. Studies have suggested that the levels of various NTs and other biomarkers could support the diagnosis and categorization of depression [34,35]. While these theories are promising, further research is needed to make biomarker identification a viable option to diagnose depression [35].

The lack of a simple laboratory test to aid the diagnosis of depression means that other methods are necessary [36]. While many depression-identifying tests have been validated, they have varying sensitivity [37-39]. These tests include questions related to 
physiological variables such as eating habits, weight loss, and sleep, as well as psychological variables such as mood, behavior, and thoughts. Tests can range from short self-reporting tests to detailed interviews involving highly trained medical staff [40,41]. Self-reporting tests are advantageous as they can be administered en masse; as such, they are time-friendly and provide extended coverage, but, their accuracy is debatable [42]. There is general agreement in the literature that one-on-one interviews with clients by trained professionals are more exact in diagnosing depression. This accuracy, however, is fully dependent upon the training of those administrating the test as well as the amount of time required for each test. These constraints, alongside a lack of administrative support, limit this option in LTCFs [38].

Currently accepted numbers of those with depression in LTCFs are based on a mixture of results from varied tests run by different researchers or organizations on wide-ranging populations. Without a specific biomarker accepted for the diagnosis of depression, multiple depression-identifying tools - including surveys - are heavily relied upon. Self-reporting tests may be used to identify LTCF residents suspected of suffering from depression. However, it is recommended that individuals are then evaluated by trained professionals [36]. Obtaining a true representation of depression in LTCFs requires coordinated mechanisms for standardized testing throughout the whole LTCF community.

\subsection{Implications of Depression in LTCFs}

Critically, depressive symptoms are present in one third of the elderly population, with the proportion of depressed elders residing in nursing homes being considerably higher than their community-dwelling counterparts [10,43]. As such, depression and anxiety are the most common mental disorders among older adults in LTCFs, yet have been inadequately studied in social research [44]. Notably, depression in LTCFs is customarily linked to the aging process and therefore overlooked. Important mental effects of depression include reduced well-being, loneliness, functional impairment, and increased mortality [44]. Moreover, depression is a major contributing factor to suicide among older people. In fact, suicide rates among older people are generally higher than those for younger people worldwide [45]. The latter fact is alarming and underscores a need for Environment-Behavior research concerning the environmental causes of depression in LTCFs.

A major barrier to depression research and treatment in LTCFs is the physical and psychological comorbidities of depression in the elderly. Age-related depression occurs along with other illnesses, such as dementia, chronic conditions, and functional limitations [46]. The management of depression in people with dementia is particularly challenging as neuronal degeneration complicates treatment responses and prolongs hospitalization [47]. Recovery and rehabilitation are further complicated by depression's direct relationship with physical illness [48]. Depression may affect cardiovascular endurance: Guinjoan et al. concluded that autonomic function is altered in major depression, indicating decreased parasympathetic activity and increased sympathetic activity. These alterations have implications for the increased risk of cardiac disease found in patients with major depression [49]. In a recent study, depression was found to be associated with decreased heart rate variability (HRV), which is a predictor of cardiovascular morbidity [50].

The co-occurrence of depression with dementia in elderly individuals poses significant challenges with regards to treatment. Antidepressants constitute a canonical therapeutic modality; however, they alter the structure and function of various brain regions, leading to detrimental neural and cognitive side effects that are particularly problematic in those with dementia [47]. Psychosocial treatments such as reminiscence and behavior therapy are constrained by their limited efficacy [47]. As such, it is necessary to explore technologically-driven treatment modalities, such as VRT, in alleviating depression and place attachment in elderly LTCF residents.

\section{VR's Effect on Depression and Mood in the Elderly}


The medical applications of VR have been extensively reviewed [51]. Applications span numerous disciplines - including medical education and training, robotic surgery, molecular biology, forensic pathology, and others [52,53]. We will focus primarily on the applications of VR in psychology, specifically as a therapeutic intervention for depression and mood in LTCFs.

It is evident that depression is associated with increased stress levels related to place attachment and relocation. A number of studies investigated reminiscence therapy using digital media and new technologies, such as VR, as a treatment for memory loss in people with dementia [54]. In the cognitive and behavioral sciences, VR is defined as "an advanced form of human-computer interface that allows the user to interact with and become immersed in a computer-generated environment in a naturalistic fashion," meaning that patients can "live" the experience of being in completely different spaces during the VR session (telepresence) [55]. However, the use and implementation of the technology is debated amongst researchers and healthcare practitioners.

Describing the spectrum and limitations of VR technologies, Klein et al. write that "virtual reality worlds with a high level of interaction demands are often too hard to grasp for people with dementia in terms of cognitive elaboration and comprehension of the metaphors used. Nevertheless, there is indication that simulated locations and objects can have a positive impact for reminiscence therapy" [54]. Such positive effects of VR are demonstrated by a number of recent cognitive and psychological studies. For instance, Yang and colleagues examined the impact of VR technology on falls and depression among elderly with mild depression, with their results showing that depression and internal stress scores were reduced after the intervention. They concluded that the VR exercise program exerted a positive effect on the psychological function of the aged and could be potentially utilized as a therapeutic intervention for reducing depression and internal stress among the elderly [56].

While literature of VRT as an intervention for depression are currently limited, numerous recent trials demonstrate the value of VRT in enhancing moods and cognition in the elderly (Table 1). These include several ambulatory studies. For instance, Chan et al. studied 236 healthy members (aged 60 and above) of elderly community centers in Hong Kong. Members of the trial group were exposed to a VR-based tour of Hong Kong's landmark sites, which included both present-day and 20-year-old images. After a single exposure, they exhibited increases in overall positive emotions - including increased interest, enthusiasm, and excitement. They also exhibited decreases in overall negative affect and its components, such as distress, hostility, and guilt [57]. In another study, Graf et al. exposed 14 home-residing pensioners to a VR "forest walk" experience via the Oculus Go headset system. The experience included a virtual dog as a companion, and several cognitively stimulating mini-games. After the VR exercise, participants demonstrated an increased overall positive affect [58]. Moreover, Banos and colleagues exposed 18 Spanish Senior University participants (aged 58 to 79 years) to VR nature walks meant to elicit joy and/or relaxation. After one, two, or three exposures, both the joy-inducing and relaxation-inducing virtual environments (VE) increased perceived joy and relaxation, and reduced sadness and anxiety [59]. These trials underscore the ability of a single VRT session to influence mood among the elderly.

Other longer-term ambulatory studies also corroborate the potential of VRT to induce positive moods among the elderly. Barsasella et al. exposed 29 Taipei Medical University Aging Center patients (ages 60-94) to VR biweekly for six weeks (twelve total exposures). VR experiences were delivered through several applications on the High-Tech Computer corporation's vive platform. Notably, participants exhibited statistically significant increases in happiness, as measured through the Chinese Happiness Inventory, post-intervention [60]. Additionally, Gamito and colleagues exposed Portuguese senior daycare center users to biweekly VR interventions over the course of six weeks. The intervention was a city-based VR in which participants carried out everyday activities, such as household organization, shopping, and watching television. Interven- 
tion group members exhibited increases in general and visual memory as well as attention [61].

Similar results to those of the aforementioned trials were obtained from studies in LTCFs. Brimelow et al. exposed 13 Australian residential aged care facility (RACF) residents, aged 66-93 years, to relaxing scenes through the Samsung Galaxy S7 smartphone-Samsung Gear VR headset system. After a single exposure, participants exhibited decreased total apathy and increased levels of facial expression, eye contact, physical engagement, verbal tone, and verbal expression [62]. In another study by Saredakis and colleagues, 17 RACF residents were exposed twice to a wandering experience based on Google Street View. This VR intervention utilized the Wander application through YouTube VR and the Oculus Go headset. The investigators found correlations between decreased apathy after the VR experiences and increased semantic fluency [63]. Finally, D'Cunha et al. exposed 11 RACF residents to an immersive bicycling experience through projected footage and stationary pedal exercisers. While no significant changes in mood or apathy were observed, the majority of participants enjoyed the experience, which allowed them to reminisce on cycling memories [64].

Table 1. Effects of VR on mood and cognitive function in the elderly.

\begin{tabular}{|c|c|c|c|}
\hline Participants & Study Design & Findings & Source \\
\hline $\begin{array}{l}\text { RACF residents: } 13 \text { total; 66-93 } \\
\text { years old }\end{array}$ & $\begin{array}{l}\text { All participants exposed to a } \\
\text { smartphone-based VR experience with } \\
\text { relaxing videos (e.g. nature); one exposure. } \\
\text { Measurements taken before and after. }\end{array}$ & $\begin{array}{c}\downarrow \text { total apathy } \\
\uparrow \text { facial expression, eye contact, physical } \\
\text { engagement, verbal tone, verbal } \\
\text { expression }\end{array}$ & {$[62]$} \\
\hline $\begin{array}{l}\text { Members of } 19 \text { elderly community } \\
\text { centers: } 236 \text { total; } 60+\text { years old }\end{array}$ & $\begin{array}{l}\text { Trial group exposed to VR cognitive } \\
\text { stimulation experience (virtual tour of Hong } \\
\text { Kong's famous sites); one exposure. } \\
\text { Control group exposed to paper-and-pencil } \\
\text { cognitive stimulation activity. }\end{array}$ & $\begin{array}{l}\uparrow \text { total positive affect (e.g. interested, } \\
\text { excited, strong, alert, determined) } \\
\downarrow \text { total negative affect (e.g. distressed, } \\
\text { upset, guilty, hostile) }\end{array}$ & [57] \\
\hline $\begin{array}{c}\text { RACF residents: } 11 \text { total; 75-94 } \\
\text { years old }\end{array}$ & $\begin{array}{l}\text { Trial group exposed to VR immersive biking } 1 \\
\text { experience (e.g. both a video and stationary } \\
\text { pedal system to follow along); one exposure. } \\
\text { Control group exposed to a standard } \\
\text { occupational therapy activity. }\end{array}$ & $\begin{array}{l}\text { No significant measured changes in mood } \\
\qquad \text { or apathy } \\
\text { Subjective experience: most participants } \\
\text { enjoyed the scenery and reminisced about } \\
\text { previous biking memories }\end{array}$ & {$[64]$} \\
\hline $\begin{array}{l}\text { University Aging Center patients: } \\
\qquad 60 \text { total; } 60-94 \text { years old }\end{array}$ & $\begin{array}{l}\text { Trial group exposed to biweekly VR } \\
\text { experiences for } 6 \text { weeks (multiple apps). } \\
\text { Control group received no intervention. }\end{array}$ & $\begin{array}{l}\text { 个 happiness } \\
\text { Greater EQ-5D improvement after VR } \\
\text { therapy than in controls }\end{array}$ & {$[60]$} \\
\hline $\begin{array}{l}50 \text { daycare center users: } 50 \text { total; } \\
67-87 \text { years old }\end{array}$ & $\begin{array}{c}\text { Trial group exposed to biweekly VR } \\
\text { experiences for } 6 \text { weeks (real-life attention, } \\
\text { memory, and exective tasks). } \\
\text { Control group exposed to weekly } \\
\text { paper-and-pencil cognitive stimulation for } 6 \\
\text { weeks. }\end{array}$ & $\begin{array}{c}\uparrow \text { general, visual memory } \\
\uparrow \text { attention }\end{array}$ & {$[61]$} \\
\hline $\begin{array}{l}\text { Senior University participants: } 18 \\
\text { total; } 58-79 \text { years old }\end{array}$ & $\begin{array}{l}\text { All participants exposed to one or both } \\
\text { natural virtual environment (VE) } \\
\text { experiences: (1) joy-inducing VE, (2) } \\
\text { relaxation-inducing VE; one to three } \\
\text { exposures. } \\
\text { Measurements taken before and after. }\end{array}$ & $\begin{array}{c}\text { For both VEs: } \\
\uparrow \text { joy, relaxation } \\
\downarrow \text { sadness, anxiety }\end{array}$ & [59] \\
\hline $\begin{array}{l}\text { Pensioners residing at home: } 14 \\
\text { total; } 66-84 \text { years old }\end{array}$ & $\begin{array}{l}\text { All participants exposed to headset-based } \\
\text { VR forest walk experience with embedded } \\
\text { mini-games; one exposure. } \\
\text { Measurements taken before and after. }\end{array}$ & $\uparrow$ total positive affect & {$[58]$} \\
\hline $\begin{array}{c}\text { RACF residents: } 17 \text { total; } 72-95 \\
\text { years old }\end{array}$ & $\begin{array}{l}\text { All participants exposed to headset-based } \\
\text { VR wandering experience based on Google }\end{array}$ & $\begin{array}{c}\text { Correlation between } \downarrow \text { apathy (after VR } \\
\text { exposure) and } \uparrow \text { semantic fluency }\end{array}$ & {$[63]$} \\
\hline
\end{tabular}


Street View; two exposures.

Measurements taken before and after.

\section{Concluding Remarks}

Numerous studies substantiate the claims that VRT has clear potential in alleviating negative feelings while promoting improved cognitive ability and positive emotions in elderly patients. They indicate that VRT reduces overall negative feelings - such as apathy, distress, and anxiety - while increasing overall positive outlook compared to pre-exposed VRT patients [57,58,60]. Not only does VRT correlate with psychological relief, but evidence also suggests that VRT can improve both physical and cognitive functionality in elderly patients. As shown by Brimelow et al. and Saredakis et al., patients who underwent VRT exhibited improvements in visual memory, linguistic fluency and expression, and physical engagement $[62,63]$. These heightened abilities can alleviate the feelings of social exclusion felt by many elderly people in LTCFs, furthering the positive effects of VR on a patient's overall psychological wellbeing.

While VRT offers many benefits, there are various challenges involved in its large-scale implementation in mental rehabilitation and therapy. Current technologies are costly and bulky, limiting their applicability in care homes due to inadequate financial resources or physical space. Furthermore, adequate training for using the technologies is required for physicians and caretakers to maximize benefit from the treatments. VRT has been attributed to various side-effects, including dizziness, nausea, and eye-fatigue, effectively limiting the population who can participate in the treatments $[65,66]$. Given that elderly people already have decreased cognitive ability due to mental deterioration, VRT may cause further aggravation and discomfort. Moreover, lack of technological understanding and insufficient physical ability may also make the elderly apprehensive of VRT, making it harder to implement as a therapeutic intervention [67]. In addition to user concern, further research is necessary to consolidate the benefits of VRT so to make it a more accepted long-term intervention within the medical field [68].

Numerous studies support that VR provides an opportunity for LTCF residents to adapt to their new environments in a controlled atmosphere, ultimately alleviating distress and subsequent psychological turmoil, and instead promoting positive feelings and emotions. Virtual environments can elicit positive psychological responses due to their ability to establish the necessary visual, cognitive, and social bonds to connect the individual to the living space. The neuroscientific influences of these virtual environments that simulate real structural environments are profound. The National Human Activity Pattern Survey finds that approximately $90 \%$ of an individual's life is spent within a built system [69]. Built systems are necessary for one's social, mental, and physical development - ultimately influencing one's perception and psychological state. As the process of aging starts to deteriorate the cognitive mind, the ability to emotionally connect to a new environment is also hindered, contributing to social exclusion and depression in the elderly. Hence, social planners, architects, neuroscientists, and psychologists must collaborate when designing infrastructures catered to the elderly due to the influence of these structured environments on psychological wellbeing [70]. However, further quantitative and qualitative research is needed in the fields of environmental psychology and environmental neuroscience to explore and substantiate the potential of VR technology in emotional and mental health.

Supplementary Materials: Not applicable.

Author Contributions: Conceptualization, M.A.; literature review and resources, K.Z.; writing-original draft preparation, K.Z., A.D., M.S.Y., S.H., H.E., and M.A.; writing-review and editing, K.Z., A.D., M.S.Y., S.H., H.E., and M.A.; figure preparation and editing, K.Z.; supervision, K.Z., S.H., H.E., and M.A. All authors have read and agreed to the published version of the manuscript.

Funding: 
Institutional Review Board Statement: Not applicable.

Informed Consent Statement: Not applicable.

Data Availability Statement: Not applicable.

Acknowledgments:

Conflicts of Interest: The authors declare no conflict of interest.

\section{References}

1. Li, A.; Montano, Z.; Chen, V.J.; Gold, J.I. Virtual reality and pain management: current trends and future directions. Pain Manag 2011, 1, 147-157, doi:10.2217/pmt.10.15.

2. Bouchard, S.; Rizzo, A. Applications of virtual reality in clinical psychology and clinical cognitive neuroscience-An introduction. In Virtual reality for psychological and neurocognitive interventions, Rizzo, A., Bouchard, S., Eds. Springer: New York, 2019; https://doi.org/10.1007/978-1-4939-9482-3 1pp. 1-13.

3. Valmaggia, L.R.; Latif, L.; Kempton, M.J.; Rus-Calafell, M. Virtual reality in the psychological treatment for mental health problems: An systematic review of recent evidence. Psychiatry Res 2016, 236, 189-195, doi:10.1016/j.psychres.2016.01.015.

4. Norcross, J.C.; Pfund, R.A.; Prochaska, J.O. Psychotherapy in 2022: A Delphi poll on its future. Professional Psychology: Research and Practice 2013, 44, 363-370, doi:10.1037/a0034633.

5. Rothbaum, B.O.; Hodges, L.F.; Kooper, R.; Opdyke, D.; Williford, J.S.; North, M. Effectiveness of computer-generated (virtual reality) graded exposure in the treatment of acrophobia. Am J Psychiatry 1995, 152, 626-628, doi:10.1176/ajp.152.4.626.

6. Park, M.J.; Kim, D.J.; Lee, U.; Na, E.J.; Jeon, H.J. A Literature Overview of Virtual Reality (VR) in Treatment of Psychiatric Disorders: Recent Advances and Limitations. Front Psychiatry 2019, 10, 505, doi:10.3389/fpsyt.2019.00505.

7. Aging, autonomy, and architecture: Advances in assisted living. Schwarz, B.; Brent, R., Eds.; The Johns Hopkins University Press: Baltimore, 1999.

8. Environmental psychology for design. 1st ed.; Kopec, D., Ed.; Fairchild Books: 2012.

9. Ortman, J.M.; Velkoff, V.A.; Hogan, H. An aging nation: The older population in the United States; US Census Bureau: 2014.

10. Choi, N.G.; Ransom, S.; Wyllie, R.J. Depression in older nursing home residents: the influence of nursing home environmental stressors, coping, and acceptance of group and individual therapy. Aging Ment Health 2008, 12, 536-547, doi:10.1080/13607860802343001.

11. de Mendonça Lima, C.A.; Ivbijaro, G. Mental health and wellbeing of older people: opportunities and challenges. Ment Health Fam Med 2013, 10, 125-127.

12. Roy, N.; Dube, R.; Despres, C.; Freitas, A.; Legare, F. Choosing between staying at home or moving: A systematic review of factors influencing housing decisions among frail older adults. PLoS One 2018, 13, e0189266, doi:10.1371/journal.pone.0189266.

https://www.dictionary.com/browse/nostalgia\#: :text=a\%20wistful\%20desire $\% 20$ to $\% 20$ return,that $\% 20$ elicits $\% 20$ or $\% 20$ dis plays\%20nostalgia. (accessed on Feb 28).

14. Environmental gerontology: Making meaningful places in old age. Rowles, G.D.; Bernard, M., Eds.; Springer Publishing Company: 2013.

15. Place attachment: Advances in theory, methods and applications. Manzo, L.C.; Devine-Wright, P., Eds.; Routledge Inc.: 2014.

16. Scannell, L.; Gifford, R. Defining place attachment: A tripartite organizing framework. Journal of Environmental Psychology 2010, 30, 1-10, doi:10.1016/j.jenvp.2009.09.006.

17. Wright, C.J. Homelike variables and rates of depression among assisted living facility residents. St. Catherine University, 2014. 
18. Schumacher, K.L.; Jones, P.S.; Meleis, A.I. Helping elderly persons in transition: A framework for research and practice. In Life transitions in the older adult: Issues for nurses and other health professionals, Swanson, E.A., Tripp-Reimer, T., Eds. Springer: New York, 1999; pp. 1-26.

19. Stevens, A.K.; Raphael, H.; Green, S.M. A qualitative study of older people with minimal care needs experiences of their admission to a nursing home with Registered Nurse care. Quality in Ageing and Older Adults 2015, 16, 94-105, doi:10.1108/qaoa-09-2014-0020.

20. Scannell, L.; Gifford, R. The experienced psychological benefits of place attachment. Journal of Environmental Psychology 2017, 51, 256-269, doi:10.1016/j.jenvp.2017.04.001.

21. Abela, J.R.; D'Alessandro, D.U. Beck's cognitive theory of depression: a test of the diathesis-stress and causal mediation components. Br J Clin Psychol 2002, 41, 111-128, doi:10.1348/014466502163912.

22. Singh, M.K.; Gotlib, I.H. The neuroscience of depression: implications for assessment and intervention. Behav Res Ther 2014, 62, 60-73, doi:10.1016/j.brat.2014.08.008.

23. Kendler, K.S.; Karkowski, L.M.; Prescott, C.A. Causal relationship between stressful life events and the onset of major depression. Am J Psychiatry 1999, 156, 837-841, doi:10.1176/ajp.156.6.837.

24. Pariante, C.M.; Lightman, S.L. The HPA axis in major depression: classical theories and new developments. Trends Neurosci 2008, 31, 464-468, doi:10.1016/j.tins.2008.06.006.

25. Cowen, P.J. Not fade away: the HPA axis and depression. Psychol Med 2010, 40, 1-4, doi:10.1017/S0033291709005558.

26. Nutt, D.; Demyttenaere, K.; Janka, Z.; Aarre, T.; Bourin, M.; Canonico, P.L.; Carrasco, J.L.; Stahl, S. The other face of depression, reduced positive affect: the role of catecholamines in causation and cure. J Psychopharmacol 2007, 21, 461-471, doi:10.1177/0269881106069938.

Smith, G.S.; Oeltzschner, G.; Gould, N.F.; Leoutsakos, J.S.; Nassery, N.; Joo, J.H.; Kraut, M.A.; Edden, R.A.E.; Barker, P.B.; Wijtenburg, S.A., et al. Neurotransmitters and Neurometabolites in Late-Life Depression: A Preliminary Magnetic Resonance Spectroscopy Study at 7T. J Affect Disord 2021, 279, 417-425, doi:10.1016/j.jad.2020.10.011.

28. Vreeburg, S.A.; Hoogendijk, W.J.; van Pelt, J.; Derijk, R.H.; Verhagen, J.C.; van Dyck, R.; Smit, J.H.; Zitman, F.G.; Penninx, B.W. Major depressive disorder and hypothalamic-pituitary-adrenal axis activity: results from a large cohort study. Arch Gen Psychiatry 2009, 66, 617-626, doi:10.1001/archgenpsychiatry.2009.50.

29. Holsen, L.M.; Lancaster, K.; Klibanski, A.; Whitfield-Gabrieli, S.; Cherkerzian, S.; Buka, S.; Goldstein, J.M. HPA-axis hormone modulation of stress response circuitry activity in women with remitted major depression. Neuroscience 2013, 250, 733-742, doi:10.1016/j.neuroscience.2013.07.042.

30. Krogh, J.; Videbech, P.; Renvillard, S.G.; Garde, A.H.; Jorgensen, M.B.; Nordentoft, M. Cognition and HPA axis reactivity in mildly to moderately depressed outpatients: a case-control study. Nord J Psychiatry 2012, 66, 414-421, doi:10.3109/08039488.2012.665081.

31. Watson, S.; Gallagher, P.; Del-Estal, D.; Hearn, A.; Ferrier, I.N.; Young, A.H. Hypothalamic-pituitary-adrenal axis function in patients with chronic depression. Psychol Med 2002, 32, 1021-1028, doi:10.1017/s0033291702005998.

Stetler, C.; Miller, G.E. Depression and hypothalamic-pituitary-adrenal activation: a quantitative summary of four decades of research. Psychosom Med 2011, 73, 114-126, doi:10.1097/PSY.0b013e31820ad12b.

33. Nandam, L.S.; Brazel, M.; Zhou, M.; Jhaveri, D.J. Cortisol and Major Depressive Disorder-Translating Findings From Humans to Animal Models and Back. Front Psychiatry 2019, 10, 974, doi:10.3389/fpsyt.2019.00974.

34. Peacock, B.N.; Scheiderer, D.J.; Kellermann, G.H. Biomolecular aspects of depression: A retrospective analysis. Compr Psychiatry 2017, 73, 168-180, doi:10.1016/j.comppsych.2016.11.002.

35. Strawbridge, R.; Young, A.H.; Cleare, A.J. Biomarkers for depression: recent insights, current challenges and future prospects. Neuropsychiatr Dis Treat 2017, 13, 1245-1262, doi:10.2147/NDT.S114542.

36. Maurer, D.M.; Raymond, T.J.; Davis, B.N. Depression: Screening and diagnosis. Am Fam Physician 2018, 98, 508-515. 
37. Eaton, W.W.; Neufeld, K.; Chen, L.S.; Cai, G. A comparison of self-report and clinical diagnostic interviews for depression: diagnostic interview schedule and schedules for clinical assessment in neuropsychiatry in the Baltimore epidemiologic catchment area follow-up. Arch Gen Psychiatry 2000, 57, 217-222, doi:10.1001/archpsyc.57.3.217.

38. Chun, A.; Reinhardt, J.P.; Ramirez, M.; Ellis, J.M.; Silver, S.; Burack, O.; Eimicke, J.P.; Cimarolli, V.; Teresi, J.A. Depression recognition and capacity for self-report among ethnically diverse nursing homes residents: Evidence of disparities in screening. J Clin Nurs 2017, 26, 4915-4926, doi:10.1111/jocn.13974.

39. Goodarzi, Z.S.; Mele, B.S.; Roberts, D.J.; Holroyd-Leduc, J. Depression Case Finding in Individuals with Dementia: A Systematic Review and Meta-Analysis. J Am Geriatr Soc 2017, 65, 937-948, doi:10.1111/jgs.14713.

40. Kroenke, K.; Spitzer, R.L.; Williams, J.B. The PHQ-9: validity of a brief depression severity measure. J Gen Intern Med 2001, 16, 606-613, doi:10.1046/j.1525-1497.2001.016009606.x.

41. Alexopoulos, G.S.; Abrams, R.C.; Young, R.C.; Shamoian, C.A. Cornell scale for depression in dementia. Biological Psychiatry 1988, 23, 271-284, doi:10.1016/0006-3223(88)90038-8.

42. Balsamo, M.; Cataldi, F.; Carlucci, L.; Padulo, C.; Fairfield, B. Assessment of late-life depression via self-report measures: a review. Clin Interv Aging 2018, 13, 2021-2044, doi:10.2147/CIA.S178943.

43. Most, E.I.; Scheltens, P.; Van Someren, E.J. Prevention of depression and sleep disturbances in elderly with memory-problems by activation of the biological clock with light--a randomized clinical trial. Trials 2010, 11, 19, doi:10.1186/1745-6215-11-19.

44. Drageset, J.; Eide, G.E.; Ranhoff, A.H. Anxiety and depression among nursing home residents without cognitive impairment. Scand J Caring Sci 2013, 27, 872-881, doi:10.1111/j.1471-6712.2012.01095.x.

45. Conejero, I.; Olie, E.; Courtet, P.; Calati, R. Suicide in older adults: current perspectives. Clin Interv Aging 2018, 13, 691-699, doi:10.2147/CIA.S130670.

46. Wu, Z.; Schimmele, C.M.; Chappell, N.L. Aging and late-life depression. J Aging Health 2012, 24, 3-28, doi:10.1177/0898264311422599.

47. Hickman, S.E.; Barrick, A.L.; Williams, C.S.; Zimmerman, S.; Connell, B.R.; Preisser, J.S.; Mitchell, C.M.; Sloane, P.D. The effect of ambient bright light therapy on depressive symptoms in persons with dementia. J Am Geriatr Soc 2007, 55, 1817-1824, doi:10.1111/j.1532-5415.2007.01428.x.

48. Huang, Y.; Carpenter, I. Identifying elderly depression using the Depression Rating Scale as part of comprehensive standardised care assessment in nursing homes. Aging Ment Health 2011, 15, 1045-1051, doi:10.1080/13607863.2011.583626.

49. Guinjoan, S.M.; Bernabo, J.L.; Cardinali, D.P. Cardiovascular tests of autonomic function and sympathetic skin responses in patients with major depression. J Neurol Neurosurg Psychiatry 1995, 59, 299-302, doi:10.1136/jnnp.59.3.299.

50. Borrione, L.; Brunoni, A.R.; Sampaio-Junior, B.; Aparicio, L.M.; Kemp, A.H.; Bensenor, I.; Lotufo, P.A.; Fraguas, R. Associations between symptoms of depression and heart rate variability: An exploratory study. Psychiatry Res 2018, 262, 482-487, doi:10.1016/j.psychres.2017.09.028.

51. Dascal, J.; Reid, M.; Ishak, W.W.; Spiegel, B.; Recacho, J.; Rosen, B.; Danovitch, I. Virtual reality and medical inpatients: A systematic review of randomized, controlled trials. Innov Clin Neurosci 2017, 14, 14-21.

52. Madrigal, E.; Prajapati, S.; Hernandez-Prera, J.C. Introducing a Virtual Reality Experience in Anatomic Pathology Education. Am J Clin Pathol 2016, 146, 462-468, doi:10.1093/ajcp/aqw133.

53. Pottle, J. Virtual reality and the transformation of medical education. Future Healthc J 2019, 6, 181-185, doi:10.7861/fhj.2019-0036.

54. Klein, P.; Uhlig, M.; Will, H. The Touch and Feel of the Past-Using Haptic and VR Artefacts to Enrich Reminiscence Therapy for People with Dementia. Technologies 2018, 6, doi:10.3390/technologies6040104.

55. Schultheis, M.T.; Rizzo, A.A. The application of virtual reality technology in rehabilitation. Rehabilitation Psychology 2001, 46, 296-311, doi:10.1037/0090-5550.46.3.296. 
56. Yang, J.E.; Lee, T.Y.; Kim, J.K. The effect of a VR exercise program on falls and depression in the elderly with mild depression in the local community. J Phys Ther Sci 2017, 29, 2157-2159, doi:10.1589/jpts.29.2157.

57. Chan, J.Y.C.; Chan, T.K.; Wong, M.P.F.; Cheung, R.S.M.; Yiu, K.K.L.; Tsoi, K.K.F. Effects of virtual reality on moods in community older adults. A multicenter randomized controlled trial. Int J Geriatr Psychiatry 2020, 35, 926-933, doi:10.1002/gps.5314.

58. Graf, L.; Liszio, S.; Masuch, M. Playing in virtual nature: improving mood of elderly people using VR technology. In Proceedings of MuC '20: Proceedings of the Conference on Mensch und Computer, Munich, Germany; pp. 155-164.

59. Baños, R.M.; Etchemendy, E.; Castilla, D.; García-Palacios, A.; Quero, S.; Botella, C. Positive mood induction procedures for virtual environments designed for elderly people. Interacting with Computers 2012, 24, 131-138, doi:10.1016/j.intcom.2012.04.002.

60. Barsasella, D.; Liu, M.F.; Malwade, S.; Galvin, C.J.; Dhar, E.; Chang, C.C.; Li, Y.J.; Syed-Abdul, S. Effects of Virtual Reality Sessions on the Quality of Life, Happiness, and Functional Fitness among the Older People: A Randomized Controlled Trial from Taiwan. Comput Methods Programs Biomed 2020, 10.1016/j.cmpb.2020.105892, 105892, doi:10.1016/j.cmpb.2020.105892.

61. Gamito, P.; Oliveira, J.; Alves, C.; Santos, N.; Coelho, C.; Brito, R. Virtual Reality-Based Cognitive Stimulation to Improve Cognitive Functioning in Community Elderly: A Controlled Study. Cyberpsychol Behav Soc Netw 2020, 23, 150-156, doi:10.1089/cyber.2019.0271.

62. Brimelow, R.E.; Dawe, B.; Dissanayaka, N. Preliminary Research: Virtual Reality in Residential Aged Care to Reduce Apathy and Improve Mood. Cyberpsychol Behav Soc Netw 2020, 23, 165-170, doi:10.1089/cyber.2019.0286.

63. Saredakis, D.; Keage, H.A.; Corlis, M.; Loetscher, T. Using Virtual Reality to Improve Apathy in Residential Aged Care: Mixed Methods Study. J Med Internet Res 2020, 22, e17632, doi:10.2196/17632.

64. D'Cunha, N.M.; Isbel, S.T.; Frost, J.; Fearon, A.; McKune, A.J.; Naumovski, N.; Kellett, J. Effects of a virtual group cycling experience on people living with dementia: A mixed method pilot study. Dementia (London) 2020, 10.1177/1471301220951328, 1471301220951328, doi:10.1177/1471301220951328.

65. Lavoie, R.; Main, K.; King, C.; King, D. Virtual experience, real consequences: the potential negative emotional consequences of virtual reality gameplay. Virtual Reality 2020, 25, 69-81, doi:10.1007/s10055-020-00440-y.

66. Garrett, B.; Taverner, T.; Gromala, D.; Tao, G.; Cordingley, E.; Sun, C. Virtual Reality Clinical Research: Promises and Challenges. JMIR Serious Games 2018, 6, e10839, doi:10.2196/10839.

67. Baniasadi, T.; Ayyoubzadeh, S.M.; Mohammadzadeh, N. Challenges and Practical Considerations in Applying Virtual Reality in Medical Education and Treatment. Oman Med J 2020, 35, e125, doi:10.5001/omj.2020.43.

68. Wiederhold, B.K.; Riva, G. Virtual Reality Therapy: Emerging Topics and Future Challenges. Cyberpsychol Behav Soc Netw 2019, 22, 3-6, doi:10.1089/cyber.2018.29136.bkw.

69. Klepeis, N.E.; Nelson, W.C.; Ott, W.R.; Robinson, J.P.; Tsang, A.M.; Switzer, P.; Behar, J.V.; Hern, S.C.; Engelmann, W.H. The National Human Activity Pattern Survey (NHAPS): a resource for assessing exposure to environmental pollutants. $J$ Expo Anal Environ Epidemiol 2001, 11, 231-252, doi:10.1038/sj.jea.7500165.

70. Chiamulera, C.; Ferrandi, E.; Benvegnu, G.; Ferraro, S.; Tommasi, F.; Maris, B.; Zandonai, T.; Bosi, S. Virtual Reality for Neuroarchitecture: Cue Reactivity in Built Spaces. Front Psychol 2017, 8, 185, doi:10.3389/fpsyg.2017.00185. 